\title{
A MESONOTAL COLOUR POLYMORPHISM APPARENTLY DEPENDENT ON LINKAGE DISEQUILIBRIUM*
}

\author{
SARAH BEDICHEK PIPKIN \\ Deportment of Biology, The Johns Hopkins University, \\ Baltimore, Maryland
}

1. INTRODUCTION

Received 2 I.v. 65

IT has been demonstrated that heterosis can develop in certain Drosophila pseudoobscura populations polymorphic for gene sequences coming from geographically distant localities (Dobzhansky and Levene, I95I; Levine, 1955), in similar populations of Drosophila willistoni (Dobzhansky and Pavlovsky, 1960), and in laboratory populations of Drosophila melanogaster carrying the Curly inversions (Erk, 1955). In these cases superiority of heterokaryotypes evolved by recombination and selection. It was multigenic in nature, involving genes both within and without the inversion limits.

Since by reduction of crossing-over an inversion can hold together selectively favourable combinations, it is important to study apparently monogenic polymorphisms not associated with altered gene sequences in order to determine whether in such cases heterosis is allelic or whether it depends on an interaction between genes at two or more loci. Mukai and Burdick (1959) concluded that superiority of heterozygotes for the lethal $I$ (2) $55 i$ of Drosophila melanogaster depends on heterosis at this single locus. They rejected the hypothesis of associative heterosis due to linkage of the lethal with a single adaptive dominant gene because the observed frequency of lethals in later generations of their laboratory populations was higher than was to be expected on the basis of such linkage (Mukai and Burdick, r 960).

In recent years several cases have been studied in which heterosis at an oligogenic locus is clearly related to the genetic background (Hochman, 196r ; Smathers, I96r; Frydenberg, 1962, 1964; Pipkin, I962; Polivanov, 1964).

The present study supports the hypothesis that polymorphism of mesonotal colour in cage populations begun as hybrids between a pale strain of Drosophila lebanonensis lebanonensis and its dark subspecies, Drosophila lebanonensis casteeli depends upon the mesonotal colour locus. and at least one linked cryptic locus affecting viability.

\section{MATERIALS AND METHODS}

A homozygous pale strain, $S S$, of the naturally polymorphic species $D . l$. lebanonensis and a dark strain ss, of the monomorphic species $D$. l. casteeli, were

* This work was supported by the Division of General Medical Sciences, National Institutes of Health, Bethesda, Md., Grant RG 068 3 to The Gorgas Memorial Laboratory, Panama and Grant RC 12018 to The Johns Hopkins University, Baltimore, Md. 
used as parents of the hybrid individuals with which the laboratory populations were started. Mesonotal colour in naturally occurring polymorphic populations is dependent upon a single pair of alleles (Pipkin, 1956, 1962). Each of four laboratory cage populations, $13 \mathrm{~b}, 13 \mathrm{~d}$, $13 \mathrm{e}$ and $13 \mathrm{f}$, was started with 400 founders, equal number of the sexes; and two half-gallon populations were started with 200 hybrids. A photograph and description of the population cage were given by Pipkin (1962). Discrete generations were used in all laboratory populations. In each generation (29 to 30 days), two to three thousand flies were withdrawn by agitating the cage and using photoattraction. They were then placed in a clean cage to produce the next generation. Of these, a sample of 400 flies was usually scored and then replaced in its respective population. The generations unscored included $6,3 \mathrm{I}, 32,43,44$ for cage $13 \mathrm{~b} ; 4,3 \mathrm{I}, 4^{\mathrm{I}}, 43$ for $13 \mathrm{~d} ; 4,3 \mathrm{I}, 4 \mathrm{I}, 4^{2}$ for $13 \mathrm{e}$ and $6,31,41,43$ for $13 f$. Fifteen of $5^{6}$ generations were unscored for half-gallon population $4 \mathrm{~d}$, and 16 of $3^{8}$ generations were unscored for bottle population $5^{\mathrm{a}}$. In the half-gallon bottles, the entire population of 250 to 400 flies was classified. Two- to 4-day-old flies were examined by the author with the head of the fly facing the observer and the illumination opposite. Populations were cultured at temperatures of 21 to $23^{\circ} \mathrm{C}$. and relative humidites of 55 to 60 per cent.

\section{EXPERIMENTAL RESULTS}

\section{Absence of modifiers in hybrid populations}

In cage populations of polymorphic $D$. $l$. lebanonensis, derived from strains of different localities in the Lebanon Mountains, obvious errors in phenotypic classification of the $S S, S s$ and ss genotypes were made owing to the presence of modifiers (Pipkin, I962). In contrast, such modifiers were not apparent in experimental populations derived from hybrids between the allopatric species $D$. $l$. lebanonensis and $D$. $l$. casteeli. Here tests of $79^{2}$ males taken from the 2nd to the I 7 th generations of all four cage populations, crossed singly with homozygous dark ss females of $D$. l. lebanonensis, showed that the phenotypes of only 18 males had been incorrectly scored. Of these errors, 6 occurred in the first two generations when it might be expected that mistakes due to inexperience in scoring might occur. An additional 96 males from generations 35 through 40 were tested individually, this time with homozygous pale $S S$ females. In only one test was it found that the male had been scored incorrectly. This high degree of scoring accuracy shows that modifiers do not alter the phenotypic expression of $S S$, $S s$ and ss genotypes when the dark allele, $s$, is derived from $D$. $l$. casteeli. The dark alleles of $D$. $l$. lebanonensis and $D . l$. casteeli must be regarded as isoalleles.

In the hybrid populations of the present study, the heterozygote Ss shows a dark mesonotum from the level of the anterior dorso-central bristles forward. Posteriorly, the mesonotum and scutellum are yellowish. The mesonotum of the homozygote, ss, is uniformly dark brown. In the $S S$ homozygote, the mesonotum anteriorly is brown, marked with a strong yellowish medial and 2 paramedial yellowish stripes, while the mesonotum posteriorly is yellowish. 


\section{Cytology}

A partial lack of pairing of homologous chromosomes was found in salivary gland cells in some $\mathrm{F}_{1}$ larvæ, both from a cross of $D . l$. lebanonensis females with $D . l$. casteeli males and from the reciprocal cross (see photograph in Pipkin, I96I). The similar karyotypes of these species possess autosomes distinguishable by length (Wharton, in Wheeler, I949; Pipkin, I96I). The rod-shaped X chromosome is of the same thickness in the two sexes but stains paler in male larvæ. Of 50 single-larva aceto-orcein preparations of $F_{1}$ hybrids of the first cross, all salivary chromosome arms were fully paired in 22 cells of different larvæ. A partial lack of pairing that involved a mediumlength arm was observed in one cell of each of 22 additional singlelarva preparations. Of these a partial lack of pairing occurred only in one medium-length arm in 19 preparations and in both mediumlength arms in 3 preparations. Six preparations showed an entire medium-length arm unpaired. Four of these also had the other medium-length arm unpaired, and two showed not only both medium-length arms unpaired, but also a partial lack of pairing in two of the long chromosome arms.

Of $4^{8}$ single-larva preparations of $F_{1}$ larvæ of the reciprocal cross, $D$. l. casteeli females with $D$. $l$. lebanonensis males, 34 proved to have homologues fully paired. A partial lack of pairing in a mediumlength chromosome arm was observed in one cell of 5 single-larva preparations; one medium arm was entirely unpaired in 5 other preparations. A partial lack of pairing in both medium-length arms was seen twice. Both medium-length arms were completely unpaired and a partial lack of pairing in a long chromosome arm was observed in two preparations. These figures are intended as qualitative rather than as quantitative descriptions of the condition of homologous chromosome pairing in hybrids between $D$. $l$. lebanonensis and $D . l$. casteeli, since there was some variation in the extent of pairing in different cells of the same larva. Two small inversions, both involving long chromosome arms, were seen in 2 of 100 single-larva preparations of $\mathrm{F}_{1}$ hybrids.

Among $\mathrm{F}_{2}$ larvæ of the cross $D . l$. lebanonensis $/ D$. l. casteeli hybrid females crossed with males of the same constitution, no lack of pairing in medium-length chromosome arms was observed in 21 single-larva preparations. However, one short section of the $\mathrm{X}$ chromosome and 2 short sections involving long autosome arms were unpaired in 3 preparations. Inversions were not observed in salivary cells of $F_{2}$ larvæ.

All chromosome arms were fully paired in 23 single-larva preparations of the $26 \mathrm{th}, 29^{\text {th }}$ and 3 ist generations of cage population $13 \mathrm{~b}$ and also in 19 such preparations of the 28 th, 32 nd and 33 rd generations of cage population I $3 \mathrm{~d}$. No inversion figures were seen in salivary cells of larvæ taken from these later generations of cage populations. 
Fate of the SS, Ss and ss genotypes in cage populations

Fig. I shows the frequency percentages of $S S, S s$ and ss genotypes for each of the four cage populations plotted against generation time. Corresponding curves of each population show general similarities.

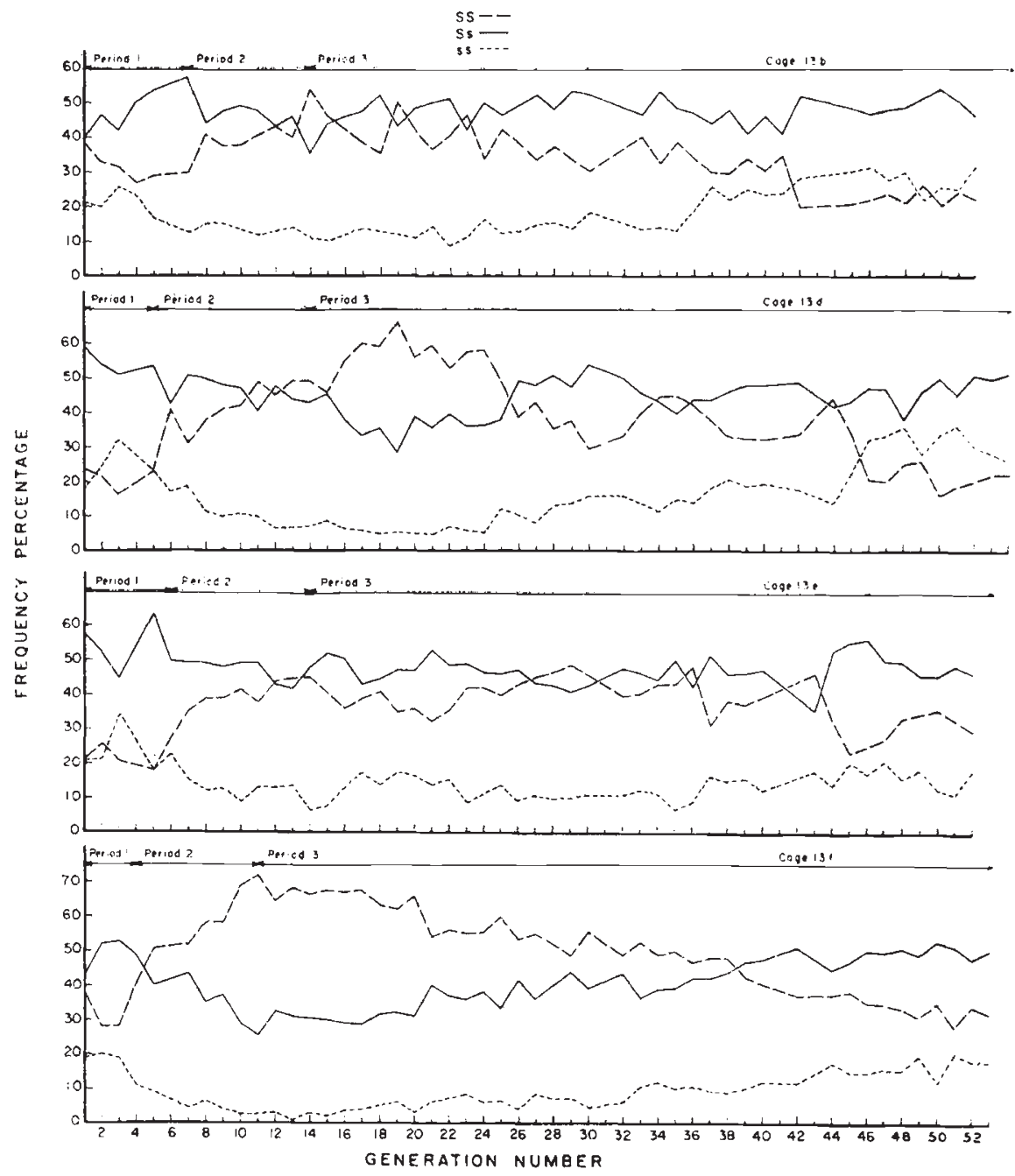

Fig. 1.-Percentage frequency curves of $S S, S s$ and ss genotypes plotted with generation time in cage populations derived from hybrids between $D . l$. lebanonensis and $D . l$. casteeli.

Oscillations in frequency of the mesonotal colour genotypes of the cage populations may be divided into three periods, the limits of which are shown in fig. I for each cage population: (1) high initial frequency of $S s$ heterozygotes; (2) a decline in frequency of $S$ s heterozygotes and a corresponding rise in frequency of $S S$ homozygotes; (3) a subsequent rise in frequency of $S$ s heterozygotes (i.e. a development of heterosis) and eventual decline in frequency of $S S$ homozygotes. 
The frequency of ss homozygotes increased somewhat in each population during the early part of period 3 because of the greater number of $S s \times S s$ matings in the population at this time. In the latter part of period 3, the frequency of ss homozygotes surpassed that of SS homozygotes in the 42 nd and 46 th generations of populations $13 \mathrm{~b}$ and $13 \mathrm{~d}$, and suggests a transfer by crossing-over of some favourable physiological gene(s) from the $S$ chromosome originally introduced into the population by the $D$. $l$. lebanonensis ancestor to the $s$ chromosome derived from $D . l$. casteeli. A similar tendency is seen in $s s$ and $S S$ frequency curves of populations 13 e and 13 f. Fig. I suggests that the differences between the frequency curves of the 3 genotypes in the cage populations were determined quite early in the history of the latter. This is in agreement with the finding by Levene, Pavlovsky and Dobzhansky (1954, 1958) in D. pseudoobscura and by Spiess (1961) in $D$. persimilis that the selective value of heterokaryotypes depended on the frequencies of other karyotypes present in the respective beginning populations. Pipkin (1962) reached a similar conclusion regarding the progress of the monogenic mesonotal polymorphism in $D$. $l$. lebanonensis experimental populations. In the present case all cage populations were begun as hybrids between $D$. $l$. lebanonensis and $D$. $l$. casteeli, but the differences in frequencies of $S S$, Ss and ss genotypes established early were subsequently resolved slowly into a similar pattern of changes.

Fig. 2 gives the frequency percentages of the three mesonotal colour genotypes for the two half-gallon bottle populations. The environment of the cages was clearly more favourable than that of the half-gallon bottles. The beneficial screened resting area of the adult flies in cages served also as a place for pupation (larvæ of this species are strongly migratory). Many of the pupæ in half-gallon bottles were drowned in the liquified culture medium. The half-gallon bottles were subject to mould infection which rarely attacked the cages. Although the surface area of food exposed in a half-gallon bottle was about the same as that offered by a one-quart mason jar of a population cage (i.e. about one-third the total amount of surface exposed by the three mason jars usually carrying food in a cage), still the maximum population size of a half-gallon bottle was only about one-eighth that normally produced in a population cage. The three periods characteristic of frequency curves of $S S, S s$ and $s s$ genotypes are discernible in the corresponding curves of half-gallon bottle populations. In an additional period, the fourth, the Ss heterozygote superiority was lost and the $S S$ homozygotes appeared to be on the way to fixation.

Observed values of the ratio of the frequency of $s$ to that of $S$ compared with those expected on the assumption of a constant set of selective values of the SS, Ss and ss genotypes

The ratio of the frequency of the dark allele, $s$, to the pale allele, $S$, decreases steadily from generations 3 to in of population $I_{3}$. 
Subsequently, with the development of heterosis, the ratio of $s$ to $S$ rises, accompanied by obvious fluctuations. To determine if the initial drop in the $s: S$ ratio is dependent on a constant set of selective values, expected values of $s: S$ during this period were calculated according to the method of Dobzhansky and Levene (1951). Taking the selective
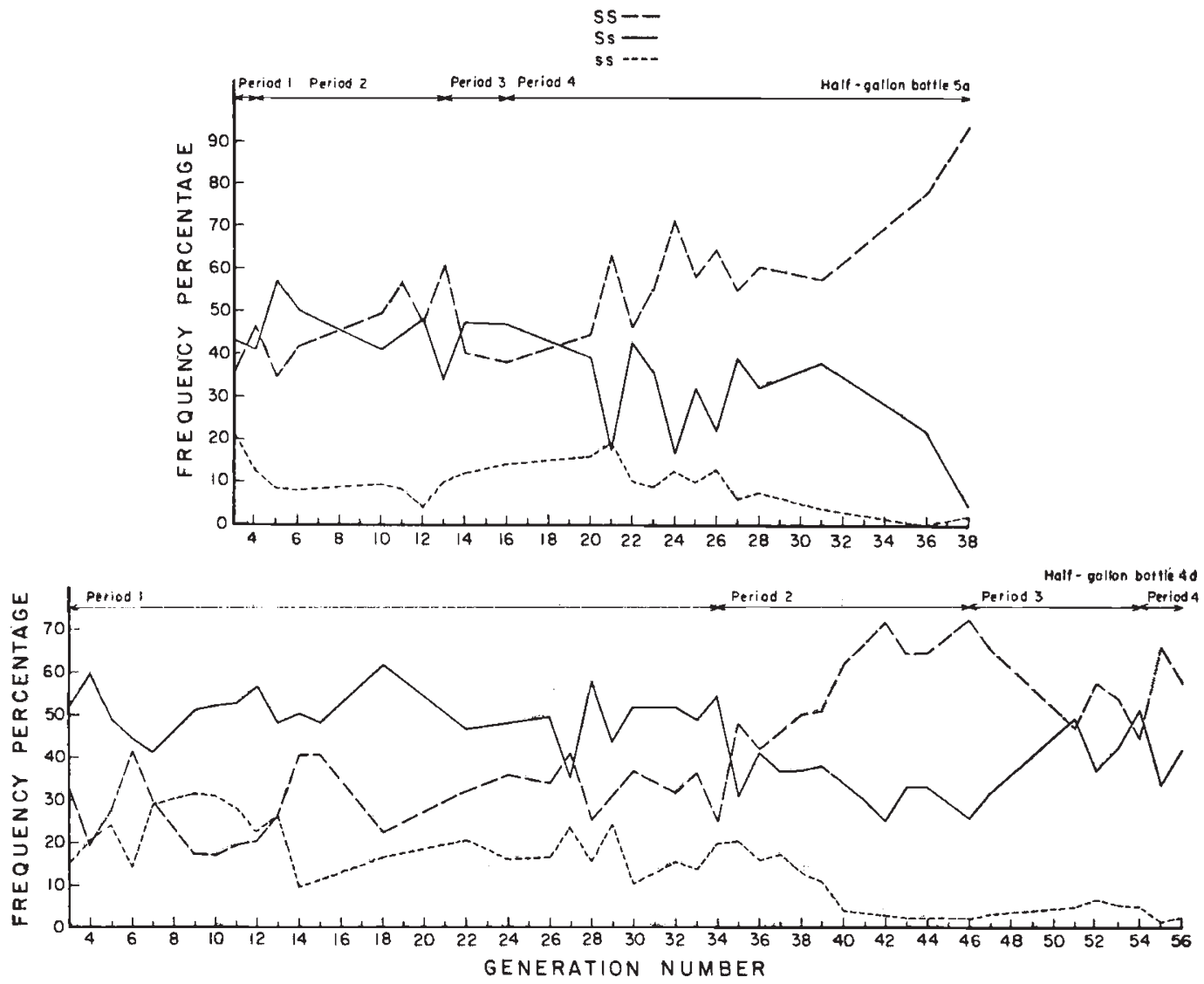

FIG. 2.-Percentage frequency curves of $S S, S s$ and ss genotypes plotted with generation time in half-gallon bottle populations derived from hybrids from $D$. l. lebanonensis and D. l. casteeli.

value of the heterozygote as 1 , different pairs of selective values, $W_{1}$ and $\mathrm{W}_{2}$ of the homozygotes ss and $S S$ were chosen by solving algebraically the equations $\mathrm{W}_{2}=a+b \mathrm{~W}_{1}$ for two non-consecutive generations. Table I compares observed $s: S$ values with those expected for generations 3 to 13 of population 13 when the most favourable pair of $\mathrm{Ws}\left(\mathrm{W}_{1}=0.09 ; \mathrm{W}_{2}=0.8 \mathrm{I}\right)$ was used. A comparison of observed and expected $s: S$ values shows that chance fluctuations account for differences between observed and expected $s: S$ values only in generations 3,7 and 8 . For studying the $s: S$ ratio from generations I 3 to 19 in the same population, the method of Dobzhansky and Levene (I95I) for determining selective values of genotypes ss and $S S$ when 
$s: S$ is at equilibrium was followed. The pair of Ws, 0.05 and 0.68 gave expected $s: S$ ratios closest to those observed, according to table I. Even these expected $s: S$ values differed by more than chance from the observed values for all but generations 13 and 18 . Thus selective values differed slightly but significantly from generation to generation during the period studied.

\section{Random mating among SS, Ss and ss genotypes of cage populations}

If assortative mating occurred between genotypes of cage populations, oscillations in their frequencies would not necessarily be

TABLE I

Comparison of observed values of the ratio $\mathrm{s}: \mathrm{S}$ with those expected on the assumption of constant selective values of the $\mathrm{SS}, \mathrm{Ss}$ and $\mathrm{ss}$ genotypes for population $\mathrm{I}_{3} f$

\begin{tabular}{|c|c|c|c|c|c|}
\hline \multicolumn{3}{|c|}{$\begin{array}{l}\quad W_{1}=0.09 ; W_{2}=0.8 \mathrm{I} \\
\text { Assumed values of homozygotes }\end{array}$} & \multicolumn{3}{|c|}{$\begin{array}{l}\qquad W_{1}=0.05 ; W_{2}=0.68 \\
\text { Assumed values of homozygotes }\end{array}$} \\
\hline $\begin{array}{l}\text { Generation } \\
\text { no. }\end{array}$ & $\begin{array}{c}\text { Observed } \\
s: S_{ \pm 1} \cdot 9^{6} \sigma\end{array}$ & $\begin{array}{l}\text { Expected } \\
\quad s: S\end{array}$ & $\begin{array}{c}\text { Generation } \\
\text { no. }\end{array}$ & $\begin{array}{c}\text { Observed } \\
s: S \pm \mathrm{I} \cdot 9^{6} \sigma\end{array}$ & $\begin{array}{l}\text { Expected } \\
\quad s: S\end{array}$ \\
\hline $\begin{array}{r}3 \\
4 \\
5 \\
6 \\
7 \\
8 \\
9 \\
\text { IO } \\
\text { I I } \\
\text { I } 2\end{array}$ & $\begin{array}{c}0.838 \pm 0.11 \\
0.544 \pm 0.08 \\
0.415 \pm 0.07 \\
\cdots \\
0.360 \pm 0.05 \\
0.317 \pm 0.05 \\
0.300 \pm 0.05 \\
0.207 \pm 0.04 \\
0.185 \pm 0.03 \\
0.241 \pm 0.04\end{array}$ & $\begin{array}{c}0.846 \\
0.646 \\
0.293 \\
\ldots \\
0.364 \\
0.270 \\
0.740 \\
0.343 \\
\text { negative } \\
0.457\end{array}$ & $\begin{array}{l}\text { I } 3 \\
\text { I } 4 \\
\text { I } 5 \\
\text { I } 6 \\
\text { I } 7 \\
\text { I } 8 \\
\text { I9 }\end{array}$ & $\begin{array}{l}0.198 \pm 0.04 \\
0.223 \pm 0.04 \\
0.211 \pm 0.04 \\
0.223 \pm 0.04 \\
0.223 \pm 0.04 \\
0.264 \pm 0.05 \\
0.283 \pm 0.05\end{array}$ & $\begin{array}{l}0.218 \\
0.398 \\
0.280 \\
0.334 \\
0.176 \\
0.264 \\
0.600\end{array}$ \\
\hline
\end{tabular}

dependent upon recombinative changes. Hence male choice tests were made to determine whether mating was at random between females of two different genotypes with respect to the $S, s$ locus and males of a single genotype, using flies from generations 32 and 35 of cage population I $3 \mathrm{~d}$. Larvæ were removed from the cage, placed in half-pint bottles to pupate, and virgin males and females were collected. Crosses for male choice experiments were made when the flies had aged for 48 hours. Trial and error showed that somewhat fewer than 50 per cent. inseminations had occurred when 20 virgin females of each of 2 different genotypes were exposed to 10 virgin males of a single genotype per mating vial for half an hour. The results appearing in table 2 show that mating was at random for the combinations tested. The rapid mating found in this population is similar to that of its D. l. lebanonensis ancestor. Beginning with hybrids between $D$. l. lebanonensis and D. l. casteeli, a selection for faster mating has occurred rather than for length of development, because the cage populations were transferred to fresh cages every 29 to 30 days, a 
period longer than the life cycle (eggs to adults of sexual maturity) of the slower mating ancestor, D. l. casteeli.

\section{Effect of increased temperature on the frequency of genotypes in replicates of cage populations}

Replicates of cage populations $13 \mathrm{~d}, 13 \mathrm{~b}$ and $13 \mathrm{e}$, were taken from the II th to the I $5^{\text {th }}$ generations, placed in half-gallon bottles, and

TABLE 2

Mating success among genotypes of cage population $13^{d}$, generations 32 and 35 , using male choice method

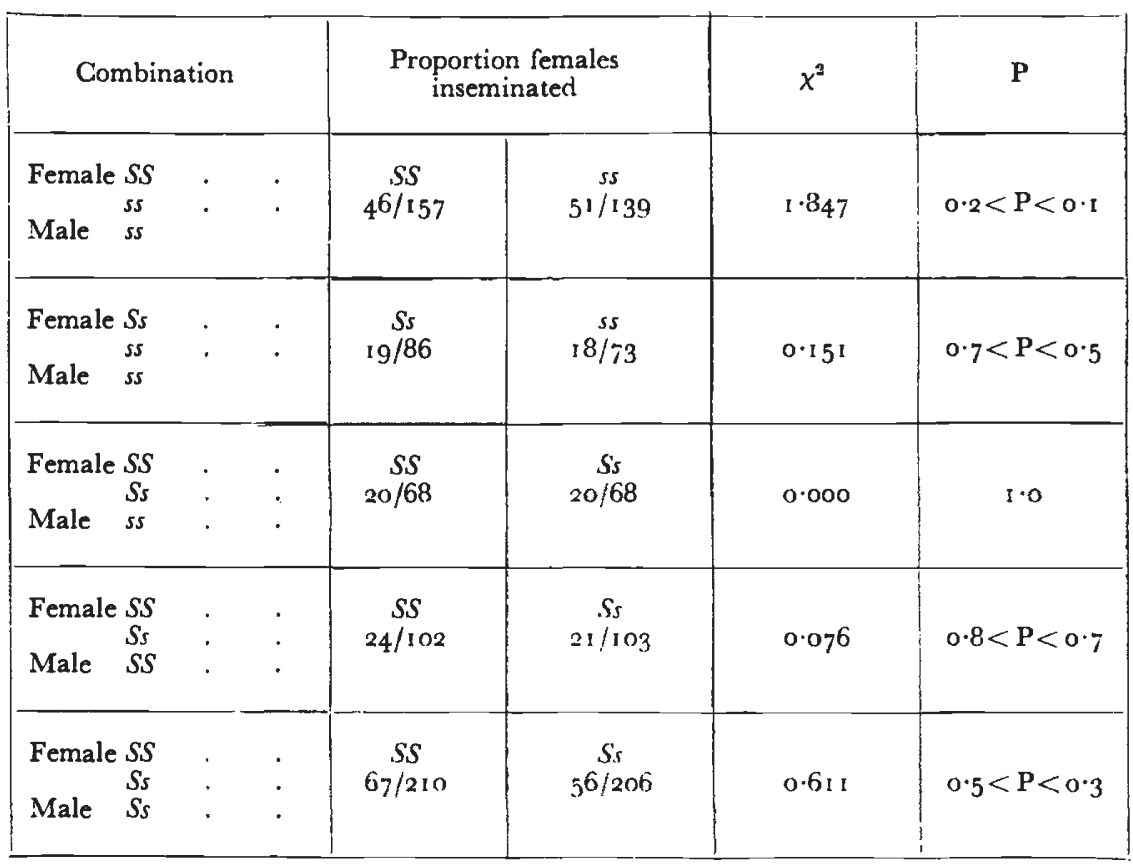

cultured for five generations at $28^{\circ} \mathrm{C}$. ' To determine to what extent the increased temperature affected the accuracy of scoring, males of generation I , population I $3 \mathrm{~d}$, of the hot series were tested individually with dark virgin females of $D$. l. lebanonensis at $2 \mathrm{I}$ to $23^{\circ} \mathrm{C}$. The frequencies of these tested genotypes appear in table 3 , together with frequencies of genotypes of the same generation of cage population I $3 \mathrm{~d}$, cultured at $2 \mathrm{I}$ to $23^{\circ} \mathrm{G}$. The accuracy of scoring phenotypes is somewhat affected in the hot series; the frequency of phenotypes scored $S S$ is about 8 per cent. higher than the true genotypic frequency of this class according to tests. In replicate half-gallon population 13d, 55 males scored $S S$ proved to be genetically $S S$ by individual male tests. Six males scored $S S$ proved to be actually $S$. Six additional males had been scored $S s$ correctly; one male scored $S s$ proved to be SS. One male scored ss proved to be genotypically s.. A comparison 
of the genotypic frequencies of the two series in table 3 shows clearly that the high temperature acts as a strong selective agent against the $S s$ genotype in the 1 it th generation of population $13 \mathrm{~d}$. This generation belongs to the second period, that of the decline of frequency of Ss heterozygotes in cage populations cultured at 21 to $23^{\circ} \mathrm{C}$. A similar strong reduction in frequency of $S s$ and ss phenotypes occurred in replicate halfgallon populations taken from the 12 th to $15^{\text {th }}$ generations of population

TABI.E 3

Comparison of the genotypic frequencies in cage populations cultured at 21 to $23^{\circ} \mathrm{C}$. and half-gallon replicate populations cultured at $28^{\circ} \mathrm{C}$.

\begin{tabular}{|c|c|c|c|c|c|c|c|}
\hline \multicolumn{5}{|c|}{ Population and generation no. } & SS & Ss & ss \\
\hline \multirow[t]{2}{*}{$13 \mathrm{~d}$} & $\begin{array}{l}\text { II } \\
21-23^{\circ} \mathrm{C} .\end{array}$ & - & - & $\cdot$ & $49 \cdot 4$ & $40 \cdot 5$ & $10 \cdot 1$ \\
\hline & $28^{\circ} \mathrm{C}$. & . & $\cdot$ & - & $8 I \cdot 2$ & $17 \cdot 4$ & $1 \cdot 4$ \\
\hline \multirow[t]{2}{*}{$13^{b}$} & ${ }_{21-23^{\circ} \mathrm{C} .}$ & $\cdot$ & $\cdot$ & $\cdot$ & $3^{8 \cdot 4}$ & $48 \cdot 4$ & $13 \cdot 2$ \\
\hline & $28^{\circ} \mathrm{C}$. & $\cdot$ & - & . & $44^{\circ} 4$ & $44 \%$ & $I I \cdot I$ \\
\hline \multirow[t]{2}{*}{$13^{d}$} & $\begin{array}{l}34 \\
2 \mathrm{I}-23^{\circ} \mathrm{C} .\end{array}$ & $\cdot$ & $\cdot$ & • & $44 \cdot 8$ & $43 \cdot 5$ & $11 \cdot 7$ \\
\hline & $28^{\circ} \mathrm{C}$ & $\cdot$ & $\cdot$ & · & $41 \cdot 3$ & $47 \cdot 7$ & $11 \cdot 0$ \\
\hline \multirow[t]{2}{*}{$13^{f}$} & $\begin{array}{l}34 \\
21-23^{\circ} \mathrm{C} .\end{array}$ & - & $\cdot$ & $\cdot$ & $48 \cdot 8$ & $39^{\circ} 9$ & $12 \cdot 2$ \\
\hline & $28^{\circ} \mathrm{C}$ & - & . & • & $41 \cdot 0$ & $5^{0 \cdot 8}$ & $8 \cdot 2$ \\
\hline
\end{tabular}

$13^{\mathrm{d}}$ and from the $13^{\text {th }}$ to $15^{\text {th }}$ generations of populations $13^{\mathrm{b}}$ and $13 \mathrm{e}$, but these were not tested genotypically. The reduction in frequency of ss homozygotes in generations i i to 15 of half-gallon replicates cultured at the high temperature probably depends upon the adverse effect of the high temperature on the survival of the $S s$ heterozygotes, since most ss homozygotes in the population at this time come from $S s \times S s$ matings. Half-gallon replicates of later cage generations taken from the $35^{\text {th }}$ to $37^{\text {th }}$ generations of cage populations $13 \mathrm{~b}, 13 \mathrm{~d}$ and $13^{\mathrm{f}}$ were similarly cultured at $28^{\circ} \mathrm{G}$. In table 3 frequencies of $S S$, Ss and ss genotypes derived from tests of individual males taken from replicate half-gallon populations of the hot series are compared with frequencies of genotypes obtained by scoring corresponding generations of cage populations cultured at 21 to $23^{\circ} \mathrm{G}$. In contrast with the adverse effects of increased temperature on the frequency of $S s$ genotypes in generations I I to 15 , the frequency of heterozygotes is little affected by increased temperature in generations 
35 to 37 , after the development of heterosis has occurred (in period 3 of fig. I).

\section{DISCUSSION}

The present work has shown that superiority of heterozygotes for the mesonotal colour alleles, $S$ and $s$, in populations derived from hybrids between $D$. $l$. lebanonensis and $D . l$. casteeli is not dependent upon heterosis at this single locus. The decline in frequency of $S_{s}$ heterozygotes in period 2 of each population is followed by development over a number of generations of heterozygote superiority and shows that the latter is attributable to interaction between alleles at more than one locus. If the selective value of the $S s$ genotype depended wholly upon heterozygosity at this locus, we should expect to have found a uniform frequency of $S s$ heterozygotes throughout the history of the experimental populations. Furthermore, observed values of the ratio of the gene frequency of $s$ to that of $S$ for the first eighteen generations of population $\mathrm{I} 3 \mathrm{f}$ differed slightly but significantly from those expected on the basis of a constant set of selective values of the SS, Ss and ss genotypes, using the method of Dobzhansky and Levene (195I). Similarly, Polivanov (1964) found no constant set of selective values for heterozygotes and homozygotes in laboratory populations of $D$. melanogaster polymorphic for oligogenic mutants.

The possibility that environmental changes caused the similarities in genotypic frequency oscillations can be discounted because the exact generation number at which periods 2 and 3 began varied in the four cage populations, and noticeable differences existed in the frequency of each of the three genotypes, respectively, at corresponding generations. The practice of transferring the populations in every generation to clean cages, the constant temperature and humidity of the laboratory and the design of the cage (one in which large food masses in quart jars were exposed to the flies) eliminated such micro-environmental changes in experimental populations with overlapping generations as Levine and Beardmore (1959) described.

$A$ priori, the multigenic nature of the heterosis of the present study could depend either on selection from the entire genome of a number of modifiers improving the selective value of the $S s$ genotype or upon interaction between the $S$, $s$-locus and one or just a few others. In the first case one might expect to find the $S s$ heterozygote frequency gradually improving with time in the populations, as eventually was found, but we should not have expected first a decline in frequency of Ss heterozygotes in all four cage populations, nor should we have expected striking changes in the frequency of $S S$ and ss homozygotes with respect to one another in later generations. Improvement of heterozygotes according to the hypothesis of gradual accumulation of modifiers would result in an equal contribution to the homozygote classes by progeny of crosses between two heterozygotes. The marked changes in frequency of $S S$ pale homozygotes with respect to that of 
ss dark homozygotes in all cage populations strongly suggest that recombination has occurred between the $S, s$ locus and a cryptic gene locus (or few gene loci) linked with the former. The long period of II to I 9 generations before heterosis began to develop in cage populations indicates that the gene loci responsible for the mesonotal colour polymorphism are linked.

When it was clear that the mesonotal colour polymorphism was not due to action at the $S, s$ locus alone, a search was made for evidence that the polymorphism might depend on linkage between the mesonotal colour locus and at least one cryptic gene. A rise in frequency of $S S$ pale homozygotes occurred in period 2 of all cage populations of the present study. In the earlier study (Pipkin, 1962), there was also a persistent rise in frequency of $S S$ homozygotes, and in some populations, the $S$ allele became fixed. This is taken to mean that the pale allele, $S$, was present in coupling with a linked cryptic gene (or genes), $C$, at the initiation of the experiment and that there was either a favourable epistatic interaction between $S$ and $C$ or that the $G$ gene itself was a favourable viability gene. The $S$ allele was introduced into the experimental populations from the $S S$ stock of $D$. l. lebanonensis, isolated from several pairs of $S s \times S s$ matings, taken from a polymorphic laboratory stock derived from a naturally polymorphic population in Beirut, Lebanon. With only a few founders, the $S S$ pale stock may have been $S C / S C$ from the time of its origin. Or, since it was carried four years before any experiments were begun, even if the $S S$ stock were not initially homozygous for $C$, it might have become so.

In cage populations of the present study, the first period, marked by superiority of the $S s$ heterozygote, is supposed to have been due to the production in the first generation of more $S s$ heterozygotes than SS homozygotes, both of which according to the hypothesis would have had at least one non-recombinant chromosome containing $S$ and $C$ in coupling. Since cytological studies showed no inversion polymorphism and almost normal pairing of homologues in salivary gland cells after the first generation, crossing-over is assumed to have occurred fairly normally beginning with the $F_{2}$ generation. The second period, that of the decline in frequency of $S s$ heterozygotes, is believed to have begun because some $S$ chromosomes were losing the gene $C$ through crossing-over in the female in return for the $c$ allele derived from $D$. $l$. casteeli. The $S S$ homozygotes are thought to have been favoured during this time when the lack of crossingover in the male was still a strong influence, since there would have been a greater chance that at least one of their two $S$ chromosomes was non-recombinant and had $C$ in coupling than that the single $S$ chromosome present in a heterozygote would carry $C$ also. The close competition, shown in fig. I, between $S S$ pale homozygotes and $S s$ heterozygotes for at least $4 \mathrm{I}$ generations in cage populations $\mathrm{I} 3 \mathrm{~b}$, $\mathrm{r} 3 \mathrm{~d}$ and $\mathrm{r} 3 \mathrm{e}$, and the superiority of $S S$ homozygotes to $S$ r heterozygotes for 39 generations in population I 3 f, are considered testimony to the $2 \mathrm{~L}$ 
long time in which the chromosomes with $S$ and $C$ in coupling were dominant in the populations. The third period, that of the development of heterosis, apparently began when $S$ s heterozygotes with $S$ and $C$ in repulsion commenced to occur with increasing frequency. The increase in frequency of recombinant $s C$ dark chromosomes would lead to an expectation of a rise in frequency of homozygous $s C / s C$ dark indipiduals on the assumption that $C$ improves the viability of ss homozygotes at least to a certain extent. This expectation was realised late in the third period in all cage populations, as fig. I shows.

The finding that pale SS homozygotes were strongly favoured during generations $I$ I to $I 5$ in replicate half-gallon bottle populations subjected to $28^{\circ} \mathrm{C}$. is to be expected since this interval of time falls within the second period when at least one of the $S$ chromosomes of an $S S$ homozygote is likely to carry $G$, the favourable cryptic allele, and $S S$ homozygotes are consequently favoured, even at $2 \mathrm{I}$ to $23^{\circ} \mathrm{C}$. in cage populations. The imposition of an almost lethal temperature of $28^{\circ} \mathrm{G}$. is believed to have increased the selective pressure exerted -either by $C$ or by the interaction of $S$ and $C$. After the development of heterosis in period 3, when $S$ and $C$ were considered to be held in repulsion to a greater extent than in period 2, increased temperature at the $35^{\text {th }}$ to $37^{\text {th }}$ generation caused no marked selective changes. This is to be expected since many homozygotes were $S c / S c$ late in the third period and would have been less favoured, because of not possessing $C$.

To account for the commonly observed stabilising selection occurring in natural outbred populations, Mather (1943) proposed that here selection favoured heterozygotes for a series of linked genes held in the repulsion phase, producing small plus and minus effects on a given quantitative character. A cryptic polymorphism of this type was identified in a wild population of $D$. melanogaster by Gibson and Thoday (1962). The latter authors, with Parsons and Bodmer (I96I), Bodmer and Parsons (1962) and Lewontin (1964) have emphasised the importance of non-randomly distributed linkage phases in the maintenance of polymorphism.

An explanation of the commonly observed initial decline in frequency of heterozygotes (or heterokaryotypes) in geographic strain crosses or in laboratory strain crosses is that the strains used in crossing have been purposely made homozygous for a particular gene arrangement or oligogenic mutant and then carried for some time in the laboratory. As a result, these strains often become homozygous also for linked viability genes or for genes interacting with the marker (gene sequence or mutant) to produce good viability. Upon crossing such strains, a linkage disequilibrium can be present because of the predominance of the coupling phase, just as apparently occurred in the present study. The later "development of heterosis" represents an increase in frequency of the repulsion phase between the linked loci involved in the polymorphism. 
The presence in the Drosophila victoria species group of a similar mesonotal polymorphism in both a palearctic species, $D$. l. lebanonensis, and a nearctic species, $D$. brookse, is evidence of the antiquity of this polymorphism. An occurrence of both monomorphic dark (D. stonei) and yellow $(D$. pattersoni) species now sympatric with the polymorphic $D$. l. lebanonensis in the Lebanon Mountains suggests an ancient breakdown in a static linkage disequilibrium of a polymorphic ancestor, leading, in the isolation of mountain environments, to the evolution of both dark and yellow descendant species.

\section{SUMMARY}

The development of superiority in heterozygotes for a pair of alleles affecting mesonotal colour which occurred in experimental populations begun as hybrids between a pale strain of the naturally polymorphic $D$. $l$. lebanonensis and its monomorphic dark subspecies, $D$. $l$. casteeli, is due to action of genes at more than one locus. Oscillations in frequency of genotypes of the mesonotal colour character in four cage populations indicate that the pale mesonotal allele, $S$, is linked with at least one cryptic gene, $C$, affecting viability. $S$ and $C$ were apparently introduced into the experimental populations entirely in coupling. The development of heterosis at the $S, s$ locus is considered to represent the increase, through crossing-over, of the repulsion phase between the pale allele, $S$, and the cryptic allele, $C$, affecting viability. A greater frequency of dark ss homozygotes than of $S S$ pale homozygotes occurring in the 42 nd generation or later in two populations and the approach to this condition in the other two cage populations are interpreted as evidence of the transfer by crossing-over of the cryptic gene from the $S$ chromosome to its homologue bearing $s$, the dark mesonotal allele. Suggestion is made that the well-known indeterminate outcome in inversion or oligogenic polymorphic populations derived from strains of different geographic localities is due to the linkage disequilibrium arising because of non-randomly distributed linkage phases of interacting genes.

Acknowledgments.-The writer is indebted to Messrs O. Ortiz, A. Powers and L. M. Powers for technical assistance in this study and to Dr Bentley Class for reading the manuscript.

\section{REFERENCES}

BODMER, W. F., AND PARSONS, P. A. 1962. Linkage and recombination in evolution. Advances in Genetics, $11,2-87$.

DOBZHANSKY, TH., AND LEVENE, H. 1951. Development of heterosis through natural selection in experimental populations of $D$. pseudoobscura. American Naturalist, $85,247-264$.

DOBZHANSKY, TH., AND PAVLOVSKy, o. 1960. How stable is balanced polymorphism? Proc. Nat. Acad. Sci., 46, 4 I-47.

ERK, F. C. 1955. Competition between chromosomal abberations associated with Curly and their wild type homologues in laboratory populations of $D$. melanogaster. Genetics, $4^{0}, 33 \mathrm{I}-34^{2}$. 
FRYDENBERG, 0 . 1962. The modification of polymorphism in some artificial populations of $D$. melanogaster. Hereditas, 48, 423-441.

FRYDENBERG, O. 1964. Population studies of a lethal mutant in Drosophila melanogaster. II. Behaviour in populations with overlapping generations. Hereditas, $5 I, 3 \mathrm{I}-66$.

Gibson, J. B., AND THODAY, J. M. 1962. Effects of disruptive selection. VI. A second chromosome polymorphism. Heredity, $17, \mathrm{r}-26$.

Hochman, в. $196 \mathrm{r}$. Isoallelic competition in populations of $D$. melanogaster containing a genetically heterogeneous background. Evolution, 15, 239-246.

LEVENE, H., PAVLOVSKY, O., AND DOBZHANSKY, TH. 1954. Interaction of the adaptive values in polymorphic experimental populations of $D$. pseudoobscura. Evolution, 8, 335-349.

LeVene, H., PAVlovsky, O., AND Dobzhansky, Th. 1958. Dependence of the adaptive values of certain genotypes in $D$. pseudoobscura on the composition of the gene pool. Evolution, 12, 18-23.

LEVINE, L. 1955. Genotypic background and heterosis in D. pseudoobscura. Genetics, $40,832-849$.

LeVINe, L., AND BeARdmore, J. A. 1959. A study of an experimental Drosophila population in equilibrium. American Naturalist, 93, 35-40.

LEWONTIN, R. c. 1964. The interaction of selection and linkage. I. General considerations; heterotic models. Genetics, 49, 49-67.

MAther, K. 1943. Polygenic inheritance and natural selection. Biol. Revs., Cambridge Phil. Soc., $18,32-64$.

MUKAI, T., AND BURDICK, A. B. 1959. Single gene heterosis associated with a second chromosome recessive lethal in $D$. melanogaster. Genetics, 44, 2 1 1-232.

MUKAI, T., AND BURDick, A. B. 1960. Concerning equilibria of heterotic lethals in random mating populations with particular reference to $l(2) 55 i$ in $D$. melanogaster. Genetics, 45, 158 1-1593.

PARSoNs, P. A., AND Bodmer, W. F. $196 \mathbf{1}$. Evolution of overdominance. Nature, Igo, 7-I 2 .

PIPKIN, s. B. 1956. Balanced polymorphism in D. lebanonensis. The Drosophila Information Service, 30,146 .

PIPKIN, s. B. 1961. Taxonomic relationships within the Drosophila victoria species group, subgenus Pholadoris (Diptera: Drosophilide). Proc. Entomol. Soc. Wash., (3), 145-16r.

PIPKIN, s. B. 1962. Mesonotal color polymorphism in D. l. lebanonensis. Genetics, 47, 1275-1290.

polivanov, S. 1964. Selection in experimental populations of Drosophila melanogaster with different genetic backgrounds. Genetics, 50, $8 \mathrm{I}-\mathrm{roo}$.

SMATHERS, K. M. 196r. The contribution of heterozygosity at certain gene loci to fitness of laboratory populations of Drosophila melanogaster. American Naturalist, $95,27-37$.

SPIEsS, E. B. 196r. Chromosomal fitness changes in experimental populations of D. persimilis from timberline in the Sierra Nevada. Evolution, $15,340-35 \mathrm{I}$.

WHEELER, M. R. 1949. The subgenus Pholadoris (Drosophila) with descriptions of two new species. Univ. Texas Publ. 4920, 143-156. 